\title{
LUMPING KINETICS OF HYDRODESULFURIZATION AND HYDRODENITROGENATION OF THE MIDDLE DISTILLATE FROM CHINESE SHALE OIL
}

\author{
XUN TANG ${ }^{(a)}$, SHUYUAN LI $^{(a) *}$, CHANGTAO YUE ${ }^{(a)}$, \\ JILAI HE $^{(\mathrm{b})}$, JILI HOU ${ }^{(\mathrm{a})}$
}

(a) State Key Laboratory of Heavy Oil Processing, China University of Petroleum, Beijing, 102249, China

(b) Shandong Energy Longkou Mining Group Co., Ltd, Longkou, Shandong, 265700, China

\begin{abstract}
The hydrogenation experiments of the middle distillate (MD) of Chinese Huadian shale oil were carried out in a bench-scale trickle-bed reactor using a commercial catalyst $\mathrm{Ni}-\mathrm{Mo}-\mathrm{W} / \mathrm{Al}_{2} \mathrm{O}_{3}$ under various operating conditions. Three kinds of lumping kinetic models were developed in order to compare their capabilities to predict the concentrations of sulfur and nitrogen in hydrotreated oil samples. The results showed that three-lump and four-lump models can be reasonably used to describe hydrodesulfurization (HDS) and hydrodenitrogenation (HDN), respectively. The predictions made using lumping models agreed well with experimental data. The discrepancies between experimental and predicted data are smaller than 5\%. The threelump model for HDS and the four-lump model for HDN were also utilized for predicting reactive features and obtaining suitable operating conditions for HDS and HDN of the middle distillate (MD) of Huadian shale oil. The species and distribution of sulfur and nitrogen compounds were also investigated.
\end{abstract}

Keywords: shale oil, lumping kinetic model, hydrodesulfurization, hydrodenitrogenation.

\section{Introduction}

The utilization of unconventional energy resources for producing clean fuels is an extremely important approach for ensuring energy security [1-5]. As a primary alternative energy, oil shale has attracted more and more attention. In China, shale oil production ranks first in the world. In 2011 the total capacity of shale oil was about $5,000,000 \mathrm{bbl}$ [6]. Therefore, it is essential to

\footnotetext{
*Corresponding author: emailsyli@cup.edu.cn
} 
develop a suitable technology for upgrading shale oil. The catalytic hydrotreatment of shale oil fractions has received a lot of attention lately as one of the effective approaches to produce clean fuels.

In the last decades, extensive studies about the hydrotreating process of shale oil have been reported in the literature [7, 8]. Early in the 1950s, the Colorado and Fushun shale oils were hydrogenated on a commercial scale, but the operations were shut down due to the cheap production of crude oil thereafter $[9,10]$. Luik et al. [11-16] have conducted researches on hydrotreating the diesel, light mazute, heavy mazute and residuum fractions of Estonian shale oil. The properties of the hydrogenated distillates, such as density, heteroatoms, flash point and degree of unsaturation, have been remarkably improved by hydrotreatment. Landau et al. [17, 18] have developed a novel catalyst system for Israeli shale oil to reduce the concentrations of sulfur and nitrogen in the hydrogenated oil, in which the degrees of hydrodenitrogenation (HDN) and hydrodesulfurization (HDS) satisfied the requirements of the further hydrocracking process [19]. Most of the crude Israeli shale oil was transformed into clean motor fuels. Now, in 2010, Eesti Energia Company studied the hydrotreatment of crude Estonian shale oil, and planned to establish a plant to hydrotreat the shale oil produced by the Enefit retort [20]. Besides, because of the high contents of heteroatoms in shale oil, in recent years, the HDS and HDN have also been reported by many investigators for upgrading shale oil to produce clean fuel [21-23]. However, only a few papers dealing with the development of kinetic models describing the HDS and HDN reactions of shale oil have been published.

In the field of crude oil hydrogenation, the lumping kinetic models were widely used for designing the corresponding reactors and catalysts, simulating reactions, and optimizing operation conditions [24-28]. Miguel [29] and Farag [30] proposed the two- and three-parallel lumping kinetic models to describe the HDS reactions, respectively. The theoretical values agreed reasonably well with experimental values. However, most lumping models for hydrogenation were mainly applied for crude oil fractions, lumping models for shale oil hydrogenation have been paid less attention to.

In this paper, the main focus is on developing optimal lumping models for simulating the reactions of HDS and HDN of shale oil middle distillate (MD), using three kinds of lumping models (two-, three- and four-lump models). In order to estimate the kinetic parameters, the experiments were carried out in a trickle-bed reactor under various operating conditions. A novel calculation procedure was utilized to derive parameters on the basis of minimizing the discrepancies between the experimental and predicted data. The species and distribution of sulfur and nitrogen compounds were also investigated. Finally, the developed models of HDS and HDN were used to predict sulfur and nitrogen concentrations for the determination of reaction conditions. 


\section{Kinetic models}

\subsection{Lumps and models}

The description of complex mixtures by lumping a huge number of chemical compounds into smaller groups of pseudocomponents has been widely employed by researchers to establish simple kinetic equations [31]. Generally, the amount of kinetic parameters increases with increasing number of lumps in a kinetic model. Meanwhile, more detailed experimental data were obtained by researchers to estimate the parameters [32-36]. Therefore, it is necessary to select a reasonable division of sulfur and nitrogen compounds for establishing kinetic models which could perfectly describe the HDS and HDN in the hydrotreatment of Huadian shale oil MD.

In this work, $\mathrm{S}$ or $\mathrm{N}$ compounds are divided into two, three and four groups, respectively, according to reactivity and rate of hydrogenation reaction. Three kinds of kinetic models for HDS and HDN are established based on the division of sulfur and nitrogen compounds. For instance, in the two-lump kinetic model the sulfur or nitrogen compounds present in the feedstock are divided into high-reactivity (lump 1) and low-reactivity (lump 2) portions. Analogously, the three-lump kinetic model groups compounds into higher-, high- and low-reactivity portions (lumps 3, 4 and 5, respectively). The lumps of the four-lump kinetic model include higher-, high-, low- and lowerreactivity portions (lumps $6,7,8$ and 9 , respectively). In addition, we assumed that all of the sulfur or nitrogen compounds are converted to $\mathrm{H}_{2} \mathrm{~S}$ or $\mathrm{NH}_{3}$ and $\mathrm{C}_{\mathrm{n}} \mathrm{H}_{\mathrm{m}}$, respectively. Based on the above division, the simplified reaction networks of lumps are shown in Figures 1-3.

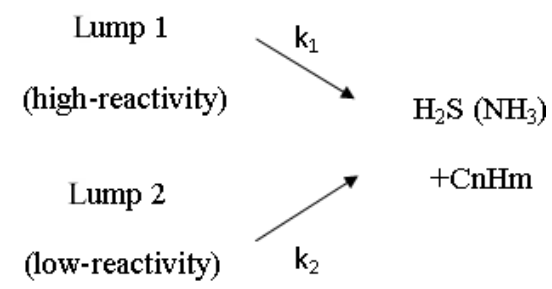

Fig. 1. Two-lump reaction network for HDS and HDN.

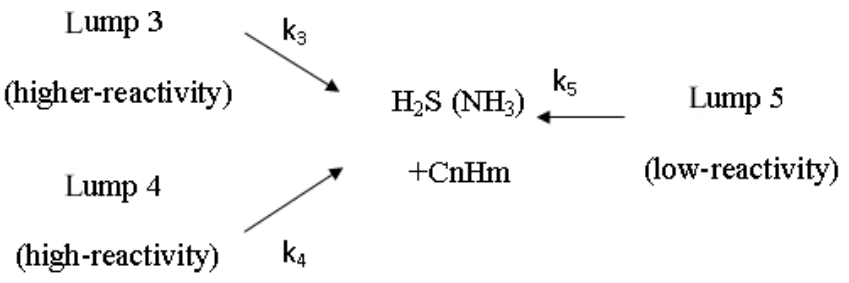

Fig. 2. Three-lump reaction network for HDS and HDN. 


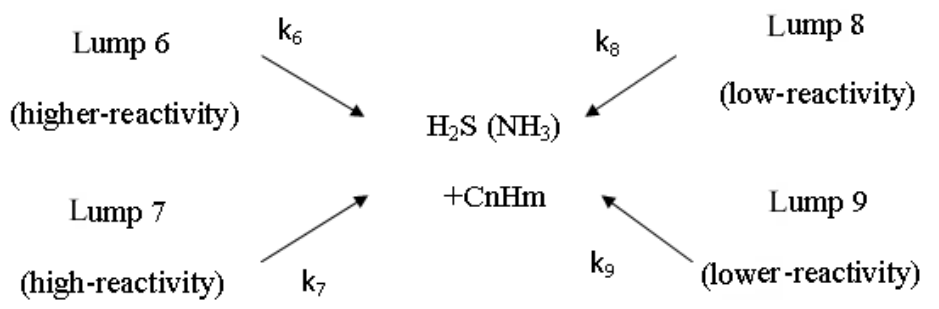

Fig. 3. Four-lump reaction network for HDS and HDN.

\subsection{Models}

To simplify the model, the following assumptions were made for practical calculations:

1) The deactivation of catalyst should be neglected.

2) The streams in the reactor are accorded with an ideal trick-bed reactor model.

3) The hydrogen pressure is constant during the experimentation.

4) The apparent reaction rate constants in the kinetic model can be expressed by the Arrhenius equation, ignoring the influence of chemical equilibrium.

5) The HDS/HDN of each lump follows the pseudo-first-order kinetics.

6) The hydrogenation pathway can be described via a direct cleavage of the $\mathrm{C}-\mathrm{S}$ or $\mathrm{C}-\mathrm{N}$ bond without other reactions between the heteroatomcontaining compounds.

On the basis of the above assumptions, the first-order reaction equation of each lump can be described as follows:

$$
C_{i}=C_{i} \exp \left(-\mathrm{k}_{\mathrm{i}} \mathrm{t}\right)=a_{i} \mathrm{C}_{\mathrm{S} 0(\mathrm{~N} 0)} \exp \left(-\mathrm{k}_{\mathrm{i}} \mathrm{t}\right),
$$

where $C_{i}$ represents the concentration of $\mathrm{S}$ or $\mathrm{N}$ for lump $\mathrm{i}, \mathrm{k}_{\mathrm{i}}$ refers to the reaction rate constant of lump $i, t$ is the residence time equal to $1 / \mathrm{LHSV}$, $\mathrm{C}_{\mathrm{S} 0(\mathrm{~N} 0)}$ is the initial concentration of sulfur or nitrogen, and $a_{i}$ is the share of sulfur or nitrogen compounds of lump $i$ in the overall concentration of sulfur or nitrogen.

Considering constant hydrogen pressure, the pre-exponential factor is the product of $A_{i}$ and $p^{m_{i}}$. Therefore, the apparent rate constant is expressed as Equation (2):

$$
\mathrm{k}_{\mathrm{i}}=A_{i} \exp \left(-\frac{\mathrm{E}_{\mathrm{i}}}{\mathrm{RT}}\right) \cdot p^{m_{i}}
$$

where $\mathrm{E}_{\mathrm{i}}, \mathrm{R}, \mathrm{T}, p$ and $m_{i}$ are the apparent activation energy, gas constant, temperature, hydrogen pressure and hydrogen pressure index, respectively.

The two-lump kinetic equations are expressed as follows: 


$$
\begin{gathered}
\frac{\mathrm{C}_{S(N)}}{\mathrm{C}_{S(N 0)}}=a_{1} \exp \left(-A_{1} \exp \left(-\frac{\mathrm{E}_{1}}{\mathrm{RT}}\right) \cdot p^{m_{1}} \cdot t\right)+a_{2} \exp \left(-A_{2} \exp \left(-\frac{\mathrm{E}_{2}}{\mathrm{RT}}\right) \cdot p^{m_{2}} \cdot t\right) \\
a_{1}+a_{2}=1, \quad\left(a_{1}, a_{2}>0\right),
\end{gathered}
$$

where $\mathrm{C}_{\mathrm{S}}$ or $\mathrm{C}_{\mathrm{N}}$ is the concentration of sulfur or nitrogen in the hydrogenated oil samples, $a_{1}$ and $a_{2}$ are the shares of lump 1 and lump 2, respectively.

Analogously, the equations of the three-lump kinetic models are expressed as follows:

$$
\begin{aligned}
\frac{\mathrm{C}_{S(N)}}{\mathrm{C}_{S 0(N 0)}=a_{3} \exp \left(-A_{3} \exp \left(-\frac{\mathrm{E}_{3}}{\mathrm{RT}}\right) \cdot p^{m_{3}} \cdot t\right)}+a_{4} \exp \left(-A_{4} \exp \left(-\frac{\mathrm{E}_{4}}{\mathrm{RT}}\right) \cdot p^{m_{4}} \cdot t\right) \\
+a_{5} \exp \left(-A_{5} \exp \left(-\frac{\mathrm{E}_{5}}{\mathrm{RT}}\right) \cdot p^{m_{5}} \cdot t\right) \\
a_{3}+a_{4}+a_{5}=1, \quad\left(a_{3}, a_{4}, a_{5}>0\right),
\end{aligned}
$$

where $a_{3}, a_{4}$ and $a_{5}$ are the shares of lumps 3,4 and 5, respectively.

The four-lump kinetic models are expressed as follows:

$$
\begin{gathered}
\frac{\mathrm{C}_{S(N)}}{\mathrm{C}_{S 0(N 0)}}=a_{6} \exp \left(-A_{6} \exp \left(-\frac{\mathrm{E}_{6}}{\mathrm{RT}}\right) \cdot p^{m_{6}} \cdot t\right)+a_{7} \exp \left(-A_{7} \exp \left(-\frac{\mathrm{E}_{7}}{\mathrm{RT}}\right) \cdot p^{m_{7}} \cdot t\right) \\
+a_{8} \exp \left(-A_{8} \exp \left(-\frac{\mathrm{E}_{8}}{\mathrm{RT}}\right) \cdot p^{m_{8}} \cdot t\right)+a_{9} \exp \left(-A_{9} \exp \left(-\frac{\mathrm{E}_{9}}{\mathrm{RT}}\right) \cdot p^{m_{9}} \cdot t\right) \\
a_{6}+a_{7}+a_{8}+a_{9}=1, \quad\left(a_{1}, a_{2}, a_{3}, a_{4}>0\right),
\end{gathered}
$$

where $a_{6}, a_{7}, a_{8}$ and $a_{9}$ are the shares of lumps $6,7,8$ and 9 , respectively.

Based on the nonlinear regression and Levenberg-Marquardt methods, a new procedure using MATLAB was employed to estimate the kinetic parameters. The goal of the procedure is to minimize the discrepancies, which are measured by the sum of squared errors (SSE), between the experimental and calculated data.

\subsection{Experimental}

The hydrogenation experiments were conducted in a bench-scale trick-bed reactor with a complete mixing of both the gas and liquid phases. The feedstock used in the experiment was the middle fraction $\left(180-360{ }^{\circ} \mathrm{C}\right)$ of Huadian shale oil. The main properties of the feed are given in Table 1.

A commercially used catalyst $\mathrm{NiMoW} / \mathrm{AlO}_{2} \mathrm{O}_{3}$ for hydrogenation of diesel fuel was used in this study. In the catalyst, $\mathrm{NiO}, \mathrm{MoO}_{3}$ and $\mathrm{WO}_{3}$ account for 3.2, 2.6 and $30.5 \mathrm{wt} \%$, respectively. In addition, the surface area and pore volume of the catalyst are $200 \mathrm{~m}^{2} / \mathrm{g}$ and $0.49 \mathrm{~mL} / \mathrm{g}$, respectively. In order to eliminate diffusion resistance, the catalyst was crashed to a particle 
size of from 0.375 to $0.85 \mathrm{~mm}$. Details of the experimental set up and procedure were given elsewhere [23].

About 60 products under various operation conditions were produced for deriving the kinetics and related parameters. The experiments were carried out under the following conditions: $280-380{ }^{\circ} \mathrm{C}, 0.5-2.5 \mathrm{~h}^{-1}, 4-7 \mathrm{MPa}$, $600 \mathrm{~L} / \mathrm{L}$.

Table 1. Basic properties of feedstock

\begin{tabular}{|l|c|}
\hline \multicolumn{1}{|c|}{ Properties } & Data \\
\hline Density $\left(20^{\circ} \mathrm{C}\right), \mathrm{g}^{-\mathrm{ml}^{-1}}$ & 0.8597 \\
Cetane number & 48.1 \\
Bromine value, $\mathrm{gBr}(100 \mathrm{~g})$ & 41.5 \\
Elemental analysis & \\
$\mathrm{C}, \mathrm{wt} \%$ & 83.77 \\
$\mathrm{H}, \mathrm{wt} \%$ & 12.98 \\
$\mathrm{O}, \mathrm{wt} \%$ & 2.16 \\
$\mathrm{~N}, \mathrm{wt} \%$ & 0.574 \\
\hline
\end{tabular}

The contents of sulfur and nitrogen were determined by the TCS-2000 UV sulfur analyzer and the REN-1000A chemiluminescence analyzer. The qualitative and quantitative analyses of sulfur compounds were accomplished with the aid of the Agilent $3420 \mathrm{HP}$ gas chromatographic-pulsed flame photometric detector (GC-PFPD), using an HP-5 (30 m $\times 0.25 \mathrm{~mm}, 0.25 \mu \mathrm{m})$ capillary GC column.

\section{Results and discussion}

\subsection{Distribution and HDS reactivity of sulfur compounds}

The results of a detailed analysis of individual sulfur compounds in the feedstock and hydrogenated products are shown in Figure 4. The distribution of $\mathrm{S}$ compounds in the feedstock is presented in Table 2.

The feedstock contains three types of sulfur compounds: 1) aliphatic and nonheterocyclic aromatic sulfur compounds (AASC), including thiols, sulfides and thiophenes, 2) benzothiophene (BT) and benzothiophenes (BTs) with alkyl substituents containing 1-5 carbon atoms, 3) dibenzothiophene (DBT) and dibenzothiophenes (DBTs) with alkyl substituents containing 1-2 carbon atoms. The sulfur species are chemically similar to those of the middle distillates of crude oil reported by Landau [22].

From Figure 4 it is seen that the conversion of most sulfur compounds is low at $280^{\circ} \mathrm{C}$, except for BT. As the temperature reaches $320^{\circ} \mathrm{C}$, the sulfur compounds with higher reactivity than $\mathrm{C}_{3} \mathrm{BT}$ 's are almost removed. Additionally, the degree of HDS is about $97 \%$ with trace $\mathrm{C}_{1-2}$ DBTs existing in the product at $360{ }^{\circ} \mathrm{C}$. The phenomenon implies that AASC and BT have 
the highest reactivity, $\mathrm{C}_{1-2} \mathrm{DBTs}$ are the most stable component, and the activities of $\mathrm{C}_{1} \mathrm{BT}$ and $\mathrm{C}_{2} \mathrm{BT}$ are lower than those of $\mathrm{C}_{3} \mathrm{BT}, \mathrm{C}_{3-5} \mathrm{BT}$ and DBT.

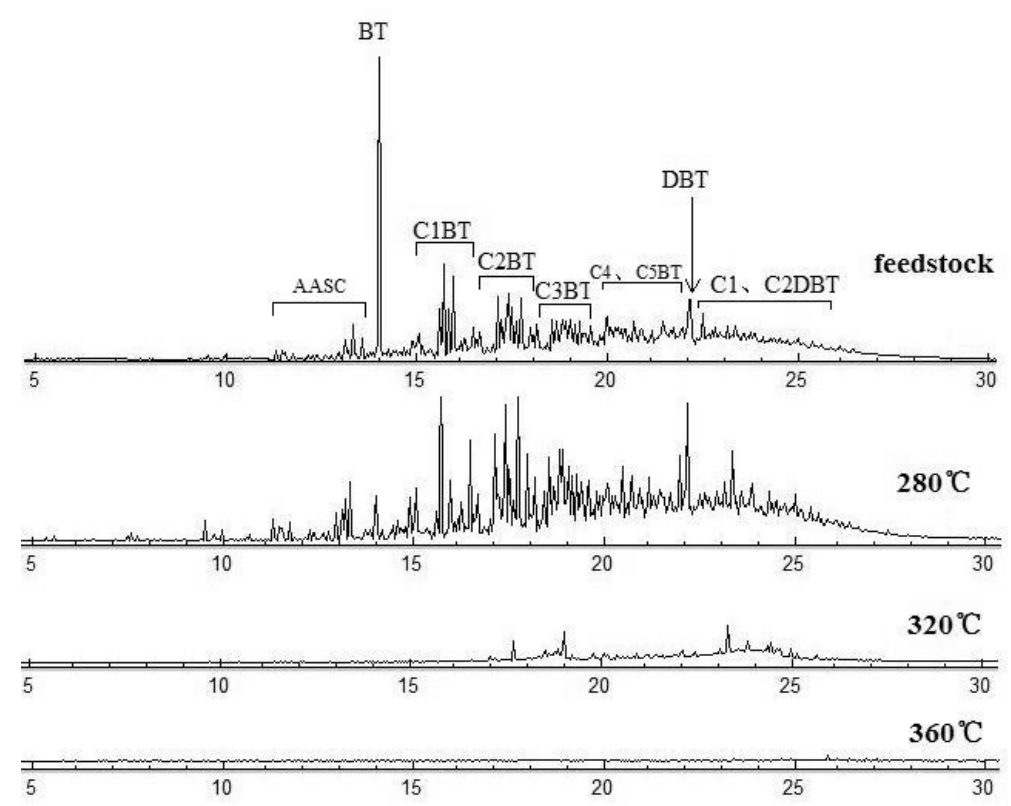

Fig. 4. Chromatogram of feedstock and oil hydrogenated at $280-360{ }^{\circ} \mathrm{C}, 4-5 \mathrm{MPa}$, $1.5 \mathrm{~h}^{-1}$ and hydrogen/oil ratio $600 \mathrm{~L} / \mathrm{L}$.

Table 2. The distribution of $\mathrm{S}$ compounds in the feedstock

\begin{tabular}{|l|c|}
\hline S-heteroatom type & $\mathrm{S}, \mathrm{wt} \%$ \\
\hline AASC & 3.8 \\
BT & 11.5 \\
$\mathrm{C}_{1} \mathrm{BT}$ & 14.1 \\
$\mathrm{C}_{2} \mathrm{BT}$ & 17.9 \\
$\mathrm{C}_{3} \mathrm{BT}$ & 20.5 \\
$\mathrm{C}_{4-5} \mathrm{BT}$ & 23.2 \\
DBT & 2.6 \\
$\mathrm{C}_{1-2} \mathrm{DBT}$ & 6.4 \\
\hline
\end{tabular}

\subsection{Distribution of $\mathrm{N}$-containing compounds}

Compared with the crude oil MD, the shale oil MD has a higher nitrogen content $(0.8-3 \%)$ [22] because it is produced by the thermal decomposition of kerogen. Consequently, the removal of $\mathrm{N}$ is important in the upgrading of shale oil MD to produce clean fuel. The degree of HDN is generally determined by the species of N-containing compounds. In order to establish the tentative correlation between the characteristics of $\mathrm{N}$ compounds and HDN kinetic models, the distribution and species of nitrogen should be 
determined. In this study, the reported data [37] were used to determine the species and distribution of nitrogen. The concentrations of different nitrogen compounds in the feedstock are given in Table 3.

Table 3 indicates that nitrogen in the feedstock is contained in seven main compounds: nitriles, anilines, pyridines, quinolines, acridines, carbazoles and indoles, and that the nitrile fraction accounts for about $65 \mathrm{wt} \%$ of total nitrogen. The results are similar to those reported previously on other shale oils in [26,33-35]. On the other hand, the distribution and species of nitrogen are different depending on the boiling points and origin of shale oils. For example, in Rundle shale oil, the nitrile, amide, basic and asphaltene fractions account for about $20,9,47$ and $24 \mathrm{wt} \%$ of total nitrogen, respectively [35]. The nitrogen in the feedstock has three characteristics: 1) the $N$ content of nitriles is high, 2) the content of basic nitrogen (anilines, pyridines, quinolines and acridines) is about $29 \mathrm{wt} \%$, and 3) the nonbasic nitrogen content is lower than that in general shale oils.

Table 3. The distribution of $\mathbf{N}$ compounds in the feedstock

\begin{tabular}{|c|c|c|c|}
\hline N-heteroatom type & $\mathrm{N}, \mathrm{wt} \%$ & N-heteroatom type & $\mathrm{N}, \mathrm{wt} \%$ \\
\hline $\mathrm{C}_{8}$-nitriles & 0.67 & $\mathrm{C}_{16}$-nitriles & 5.08 \\
$\mathrm{C}_{9}$-nitriles & 4.82 & Anilines & 11.22 \\
$\mathrm{C}_{10}$-nitriles & 5.95 & Pyridines & 9.55 \\
$\mathrm{C}_{11}$-nitriles & 7.00 & Quinolines & 5.20 \\
$\mathrm{C}_{12}$-nitriles & 13.12 & Acridines & 2.32 \\
$\mathrm{C}_{13}$-nitriles & 11.99 & Carbazoles & 1.17 \\
$\mathrm{C}_{14}$-nitriles & 9.45 & Indoles & 5.59 \\
$\mathrm{C}_{15}$-nitriles & 6.88 & & \\
\hline
\end{tabular}

\subsection{Lumping models for HDS and HDN reactions}

\subsubsection{Lumping models for HDS reactions}

Table 4 shows the parameters, RMSE and R of three models for HDS. The experimental and predicted $\mathrm{S}$ contents in the products are plotted in Figures 5-7.

The value of $a_{1}$ implies that $95.2 \mathrm{wt} \%$ of total sulfur is present in lump 1 with high HDS reactivity. The values of the apparent activation energy of lumps 1 and 2 are 78 and $170 \mathrm{~kJ} / \mathrm{mol}$, respectively. Similar values of $\mathrm{a}_{1}, \mathrm{a}_{2}$, $\mathrm{E}_{1}$ and $\mathrm{E}_{2}$ were reported by Rodriguez [29] using vacuum gas oil. From Figure 5 it can be seen that the two-lump kinetic model demonstrates good performance only at high temperature/pressure and low LHSV. The twolump kinetic model gives high RMSE and low R (Table 4), implying that the predictions on the basis of this model are not sufficiently reliable.

The three- and four-lump kinetic models could reasonably predict the sulfur concentration for HDS because both values of R exceed 0.99. However, the RMSE of the three-lump model is lower than that of the four-lump one. Figures 6 and 7 also show that the three-lump kinetic model affords a 
Table 4. Kinetic parameters of two-, three- and four-lump models for HDS

\begin{tabular}{|c|c|c|c|c|c|c|c|}
\hline Model & RMSE & $\mathrm{R}$ & Lump share & $a_{i}$ & $\mathrm{Ai}_{0}, \mathrm{~h}^{-1} \mathrm{~Pa}$ & $\mathrm{E}_{\mathrm{i}}, \mathrm{kJ} \cdot \mathrm{mol}^{-1}$ & $\mathrm{~m}_{\mathrm{i}}$ \\
\hline \multirow{2}{*}{ 2-lump } & \multirow{2}{*}{0.146} & \multirow{2}{*}{0.9571} & $a_{1}$ & 0.942 & $1.00 \times 10^{4}$ & 78.00 & 0.5193 \\
\hline & & & $a_{2}$ & 0.058 & $3.00 \times 10^{5}$ & 170.00 & 1.2745 \\
\hline \multirow{3}{*}{ 3-lump } & \multirow{3}{*}{0.019} & \multirow{3}{*}{0.9993} & $a_{3}$ & 0.453 & $1.00 \times 10^{4}$ & 60.00 & 0.4201 \\
\hline & & & $a_{4}$ & 0.489 & $1.00 \times 10^{5}$ & 132.00 & 1.0565 \\
\hline & & & $a_{5}$ & 0.058 & $1.36 \times 10^{6}$ & 170.83 & 1.1786 \\
\hline \multirow{4}{*}{ 4-lump } & \multirow{4}{*}{0.048} & \multirow{4}{*}{0.9971} & $a_{6}$ & 0.453 & $1.30 \times 10^{4}$ & 60.00 & 0.3800 \\
\hline & & & $a_{7}$ & 0.237 & $1.90 \times 10^{5}$ & 110.00 & 0.7500 \\
\hline & & & $a_{8}$ & 0.252 & $3.45 \times 10^{6}$ & 140.00 & 0.9100 \\
\hline & & & $\mathrm{a}_{9}$ & 0.058 & $1.08 \times 10^{6}$ & 174.91 & 1.2521 \\
\hline
\end{tabular}

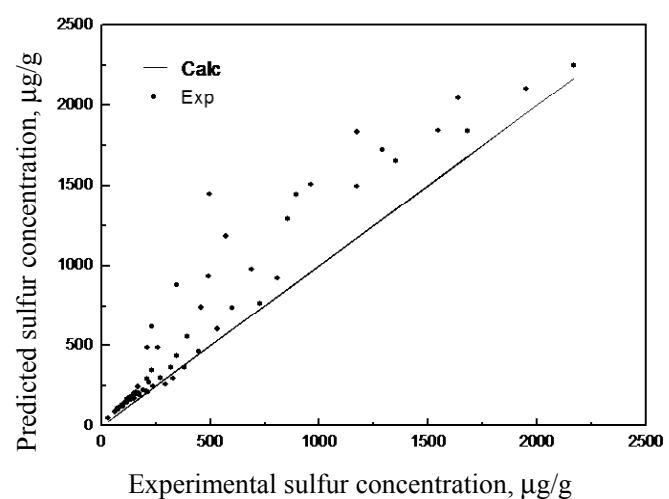

Fig. 5. Experimental and the 2-lump model predicted sulfur concentrations.

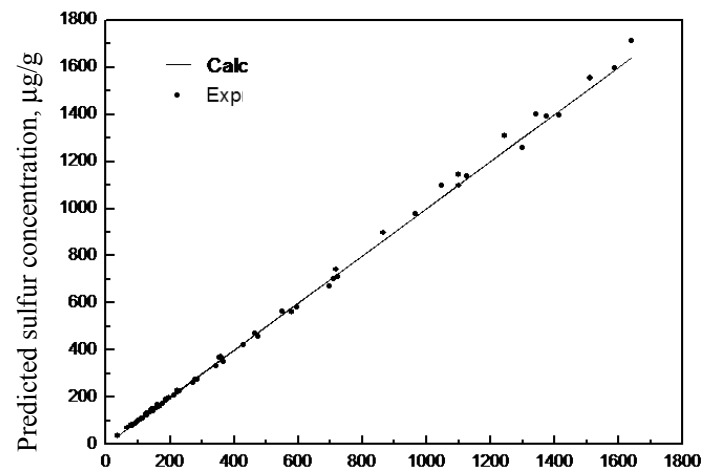

Experimental sulfur concentration, $\mu \mathrm{g} / \mathrm{g}$

Fig. 6. Experimental and the 3-lump model predicted sulfur concentrations. 


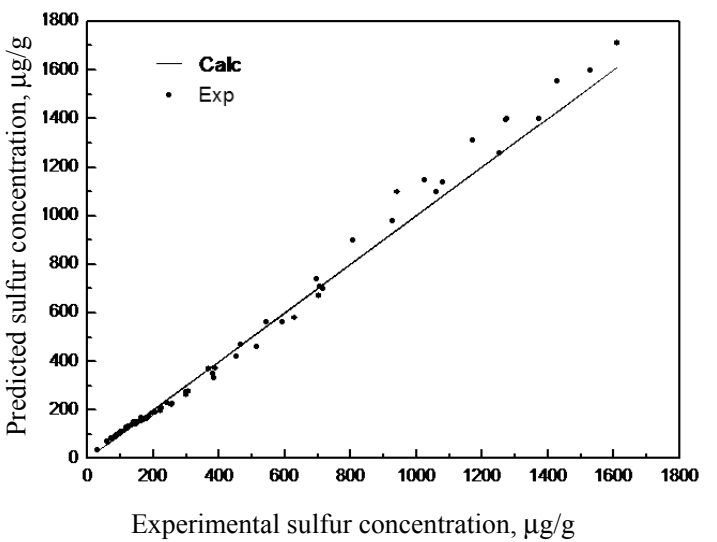

Fig. 7. Experimental and the 4-lump kinetic model predicted sulfur concentrations.

more reliable prediction than the four-lump one, especially at low temperature/pressure and high LHSV (high values of S content). Thus, it is concluded that the three-lump kinetic model is an optimal model for simulating HDS of shale oil MD, with absolute errors below 5\%. The values of $\mathrm{a}_{3}, \mathrm{a}_{4}$ and $\mathrm{a}_{5}$ are $0.453,0.489$ and 0.058 , respectively. This fact means that the shares of sulfur in lumps 3,4 and 5 are $45.3,48.9,5.8 \mathrm{wt} \%$, respectively. Comparison of the values of $\mathrm{E}_{3}, \mathrm{E}_{4}$ and $\mathrm{E}_{5}$ indicates that lump 5 represents a low-reactivity fraction while lump 3 could be converted easily. The influence of $\mathrm{H}_{2}$ pressure on the removal of $\mathrm{S}$ increases with decreasing HDS reactivity of the lump. For instance, the $\mathrm{H}_{2}$ pressure index, m5, in lump 5 is higher than 1.1, showing the significant effect of hydrogen pressure on the conversion of the lump. In contrast, the influence of $\mathrm{H}_{2}$ pressure on the HDS of lump 3 is negligible.

The properties of sulfur compounds, such as activity, as well as distribution and species should be relative to the lumps for HDS, in order to obtain more detailed information for designing catalysts and optimizing operation conditions. From the concepts reported by Landau [22], the relative reactivity of $\mathrm{S}$ species in the feedstock could diminish in the following sequence:

$$
\mathrm{AASC}>\mathrm{BT}>\mathrm{C}_{1} \mathrm{BT}>\mathrm{C}_{2} \mathrm{BT}>\mathrm{C}_{3} \mathrm{BT}>\mathrm{C}_{4-5} \mathrm{BT}>\mathrm{DBT}>\mathrm{C}_{1-2} \mathrm{DBTs}
$$

In the three-lump model, lump 5 represents the low-reactivity species with the highest apparent activation energy. $\mathrm{C}_{1-2}$ DBTs reveal the lowest activity among the $\mathrm{S}$ compounds in normal MD [22]. As the share of $\mathrm{C}_{1-2}$ DBTs approximates to that of lump 5 , the conversion of lump 5 is mainly attributed to the removal of these compounds. 


\subsubsection{Application of the HDS model}

The three-lump model has two primary functions: 1) predicting the sulfur concentrations of products in each lump, and 2) optimizing the operation conditions. For the first application, Figure 8 was plotted to illustrate sulfur conversion during hydrogenation. Figures 9 and 10 show the effect of reaction conditions on the amount of residual sulfur.

From Figure 9 it can be seen that with increasing residence time, the sulfur compounds in lumps 3 and 4 are rapidly removed by the catalytic hydrotreatment. The change of $\mathrm{S}$ content in lump 5 is negligible when the residence time is shorter than $0.3 \mathrm{~h}$. The second application could be realized by comparing the effects of residence time, temperature and hydrogen pressure on the sulfur concentrations predicted by the three-lump kinetic model. Figure 9 indicates that the sulfur is removed significantly when the temperature reaches $360{ }^{\circ} \mathrm{C}$. If the residence time exceeds $0.5 \mathrm{~h}$, the sulfur

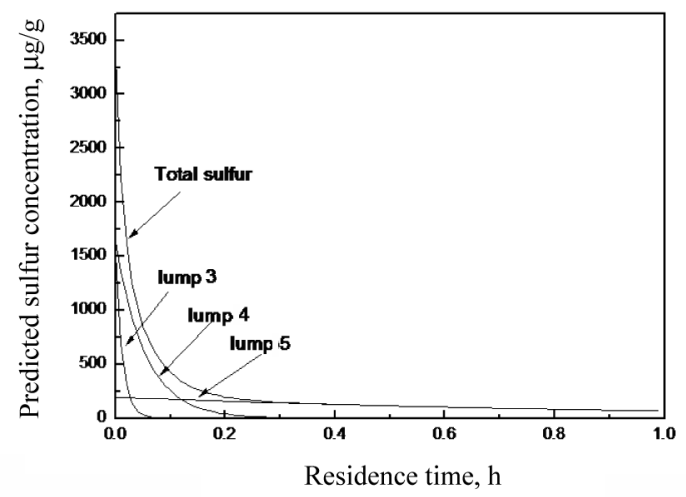

Fig. 8. Sulfur concentration predicted by the three-lump model at $360{ }^{\circ} \mathrm{C}, 6 \mathrm{MPa}$ and hydrogen/oil $600 \mathrm{~L} / \mathrm{L}$.

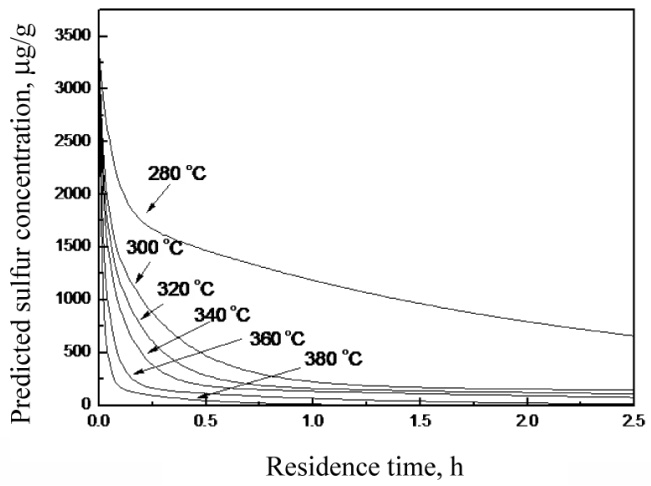

Fig. 9. Sulfur concentration predicted by the three-lump model at different temperatures, $6 \mathrm{MPa}$ and $600 \mathrm{~L} / \mathrm{L}$. 


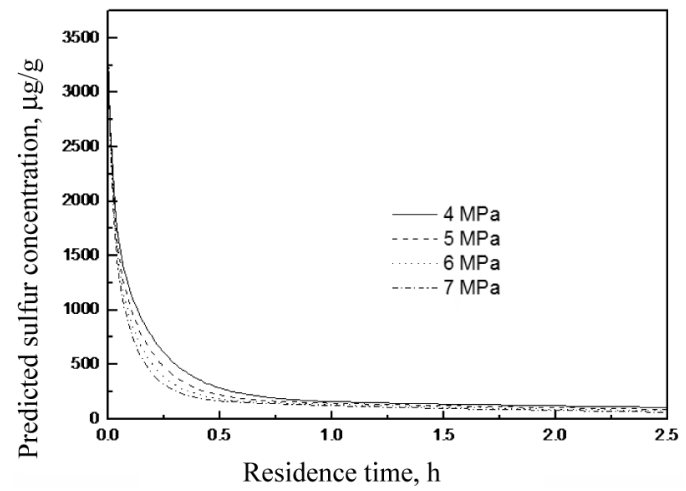

Fig. 10. Sulfur concentration predicted by the three-lump model at different pressures, $340{ }^{\circ} \mathrm{C}$ and $600 \mathrm{~L} / \mathrm{L}$.

conversion increases slightly. It is implied by Figure 10 that the influence of $\mathrm{H}_{2}$ pressure is far lower than that of temperature, while the fastest decrease in $\mathrm{S}$ concentration is observed at a pressure of from 5 to $6 \mathrm{MPa}$. Considering the various factors, the optimal operating conditions for HDS are $6 \mathrm{MPa}$, $360{ }^{\circ} \mathrm{C}, 1 \mathrm{~h}$ and hydrogen/oil $600 \mathrm{~L} / \mathrm{L}$. This agrees well with the experimental data reported by $\mathrm{Yu}[23]$.

\subsubsection{The lump models for HDN reactions}

The parameters, RMSE and R of three models for HDN are given in Table 5. Similarly to the HDS models, the nitrogen species of lumps 1-9 in these models were also determined by relative HDN reactivity. Table 6 shows the parameters, RMSE and R of three approaches. The apparent activation energies of HDN are higher than those of HDS. Hence, the nitrogen removal should be carried out under more severe operating conditions [23] than that of sulfur. At the same time, the $\mathrm{C}-\mathrm{N}$ bonds are more stable than $\mathrm{C}-\mathrm{S}$ bonds, needing more energy for cleavage. The initial hydrogen pressure indexes of HDN are higher than those of HDS, which indicates that the HDN is more affected by hydrogen pressure. Considering the RMSE and R of each model, the four-lump model is an optimal model for HDN of shale oil MD, unlike for HDS. These results may be due to the different mechanisms of reaction between nitrogen and sulfur compounds.

From Table 5 is it seen that the shares of lumps 6, 7, 8 and 9 are 19.3, $59.2,16.5$ and $5.0 \mathrm{wt} \%$, respectively. The values of $\mathrm{E}_{6}, \mathrm{E}_{7}, \mathrm{E}_{8}$ and $\mathrm{E}_{9}$ are $81.99,123,149.86$ and $239.62 \mathrm{~kJ} / \mathrm{mol}$, respectively. The effect of hydrogen pressure on HDN increases with decreasing nitrogen reactivity.

Figures 11-13 depict the experimental $\mathrm{N}$ contents of products and those predicted by different models. The differences between the experimental and predicted nitrogen concentrations decrease with increasing amount of lumps. The four-lump kinetic model can accurately predict the $\mathrm{N}$ concentrations 
within a wide range of operating conditions $\left(280-380{ }^{\circ} \mathrm{C}, 4-7 \mathrm{MPa}\right.$, LHSV $0.5-2.5 \mathrm{~h}^{-1}$, hydrogen/oil $600 \mathrm{~L} / \mathrm{L}$ ).

Table 5. The kinetic parameters of two-, three- and four-lump models for HDN

\begin{tabular}{|c|c|c|c|c|c|c|c|}
\hline Model & RMSE & $\mathrm{R}$ & Lump share & $\mathrm{a}_{\mathrm{i}}$ & $\mathrm{A}_{\mathrm{i} 0}, \mathrm{~h}^{-1} \mathrm{~Pa}$ & $\mathrm{E}_{\mathrm{i}}, \mathrm{kJ} \cdot \mathrm{mol}^{-1}$ & $\mathrm{~m}_{\mathrm{i}}$ \\
\hline \multirow{2}{*}{ 2-lump } & \multirow{2}{*}{0.411} & \multirow{2}{*}{0.9820} & $\mathrm{a}_{1}$ & 0.193 & $2.39 \times 10^{3}$ & 76.00 & 0.7000 \\
& & $\mathrm{a}_{2}$ & 0.807 & $1.99 \times 10^{5}$ & 180.00 & 1.5104 \\
\hline \multirow{3}{*}{ 3-lump } & \multirow{3}{*}{0.173} & \multirow{2}{*}{0.9952} & $\mathrm{a}_{3}$ & 0.193 & $4.00 \times 10^{4}$ & 82.83 & 0.5500 \\
& & $\mathrm{a}_{4}$ & 0.757 & $5.00 \times 10^{4}$ & 147.88 & 1.2000 \\
& & $\mathrm{a}_{5}$ & 0.050 & $6.00 \times 10^{4}$ & 240.00 & 1.8001 \\
\hline \multirow{3}{*}{ 4-lump } & \multirow{3}{*}{0.078} & \multirow{2}{*}{0.9982} & $\mathrm{a}_{6}$ & 0.193 & $3.02 \times 10^{3}$ & 81.99 & 0.6803 \\
& & & $\mathrm{a}_{7}$ & 0.592 & $1.00 \times 10^{4}$ & 123.00 & 1.0000 \\
& & & $\mathrm{a}_{8}$ & 0.165 & $3.17 \times 10^{4}$ & 149.86 & 1.2045 \\
& & $\mathrm{a}_{9}$ & 0.050 & $2.23 \times 10^{5}$ & 239.62 & 1.4684 \\
\hline
\end{tabular}

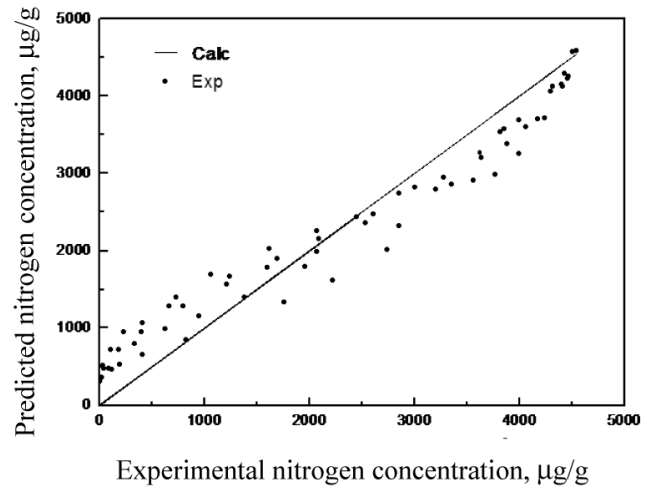

Fig. 11. Experimental and the 2-lump model predicted nitrogen concentrations.

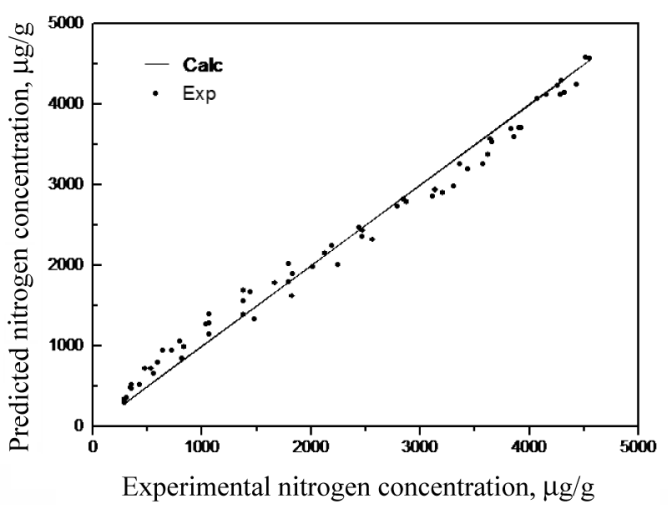

Fig. 12. Experimental and the 3-lump model predicted nitrogen concentrations. 


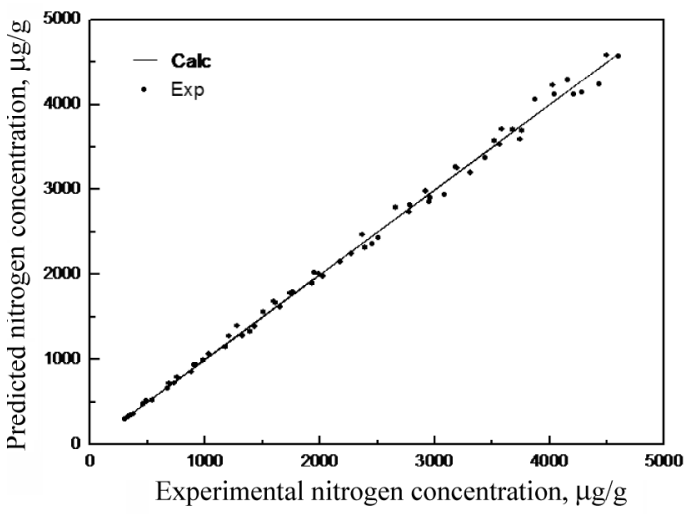

Fig. 13. Experimental and the 4-lump model predicted nitrogen concentrations.

As mentioned in 3.2, the main nitrogen compounds in the feedstock are nitriles, anilines, pyridines, quinolines, acridines, indoles and carbazoles. Based on the results reported by Holmes and Landau [22, 33], the nitrogen compounds could be arranged in terms of activity as follows:

nitriles $>$ anilines $>$ pyridines $>$ quinolines $>$ acridines $>$ indoles $>$ carbazoles

According to the value of $\mathrm{a}_{6}$, lump 6 having the highest HDN reactivity accounts for about $19.3 \mathrm{wt} \%$ of total nitrogen. Lump 6 undergoes partial conversion of nitriles with higher reactivity. Generally, during normal hydrogenation of MD, pyrrholes (indoles and carbazoles) are hard to be removed because of their lowest adsorption ability and 'hindrance' effect. Lump 9 is also the most stable fraction. So, lump 9 undergoes the main hydrogenation reactions of indoles and carbazoles.

\subsubsection{Application of the HDN model}

In order to simulate the $\mathrm{N}$ concentrations of products in each lump, Figure 14 was plotted to illustrate the nitrogen removal during hydrogenation. It should be noted that as the residence time reaches $0.3 \mathrm{~h}$, lump 6 is removed drastically. With increasing residence time, the nitrogen compounds in lump 7 are also removed to a high extent, while in lump 8 to much lesser extent. The respective change in lump 9 is insignificant under the operating conditions $360{ }^{\circ} \mathrm{C}, 6 \mathrm{MPa}, 0-1.6 \mathrm{~h}$ and hydrogen/oil $600 \mathrm{~L} / \mathrm{L}$. The total nitrogen is significantly decreased to $270 \mu \mathrm{g} / \mathrm{g}$ as the residence time reaches $1.0 \mathrm{~h}$. Thereafter, the concentration of nitrogen stays constant.

For optimizing the operation conditions, Figures 15 and 16 were plotted to show the effect of residence time, temperature and hydrogen pressure on the nitrogen concentrations predicted by the four-lump kinetic model. In Figure 15 it can be seen that the temperature significantly affects the degree of HDN. At $380{ }^{\circ} \mathrm{C}$, the nitrogen concentration does not change when the residence time exceeds $1 \mathrm{~h}$. Figure 17 indicates that the HDN for shale oil 


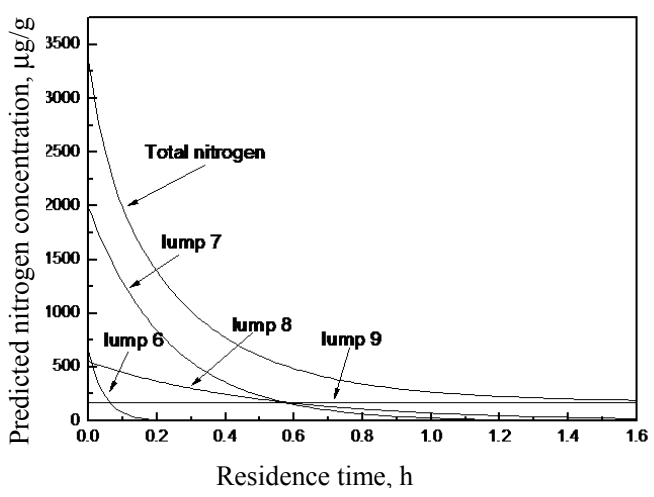

Fig. 14. Nitrogen concentration predicted by the four-lump model at $360{ }^{\circ} \mathrm{C}, 6 \mathrm{MPa}$ and hydrogen/oil $600 \mathrm{~L} / \mathrm{L}$.

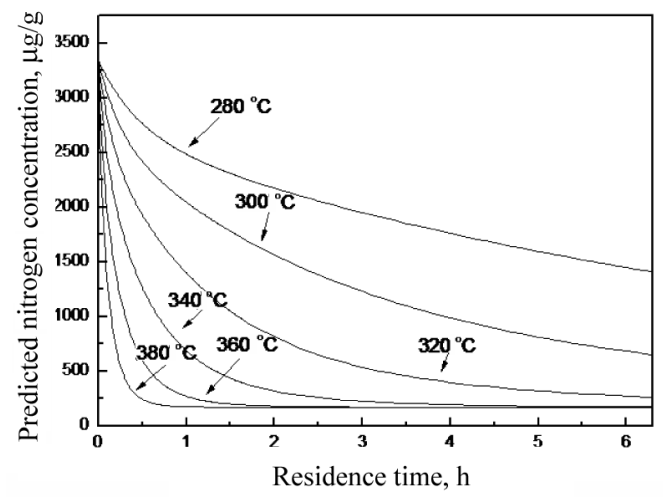

Fig. 15. Nitrogen concentration predicted by the four-lump model at different temperatures, $6 \mathrm{MPa}$ and $600 \mathrm{~L} / \mathrm{L}$.

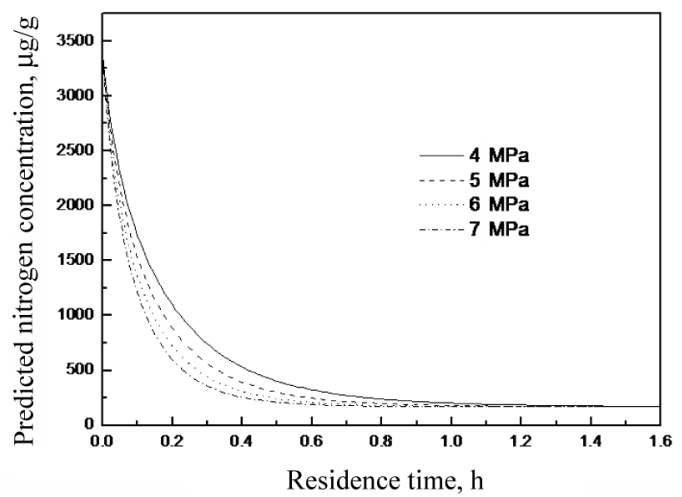

Fig. 16. Nitrogen concentration predicted by the four-lump model at different pressures, $380{ }^{\circ} \mathrm{C}$ and $600 \mathrm{~L} / \mathrm{L}$. 
MD is more affected by hydrogen pressure than HDS. Considering the above factors, the optimal operating conditions for $\mathrm{HDN}$ are $7 \mathrm{MPa}, 380{ }^{\circ} \mathrm{C}, 1 \mathrm{~h}$ and hydrogen/oil $600 \mathrm{~L} / \mathrm{L}$.

\section{Conclusions}

1) The optimal models for HDS and HDN are three-lump and four-lump kinetic models. The predicted data were in good agreement with the experimental data in a wide range of operating conditions. The differences between experimental and predicted data are lower than $5 \%$.

2) In the three-lump model for HDS, lumps 3,4 and 5 contained sulfur 45.3, 48.9 and $5.8 \mathrm{wt} \%$, respectively. Their apparent activation energies were about 60, 132 and $170 \mathrm{~kJ} / \mathrm{mol}$, respectively. Predicting the HDS reaction in each lump showed that the sulfur in lumps 3 and 4 was removed rapidly but the conversion rate of lump 5 was very low. The economic and reasonable operating conditions for HDS were $6 \mathrm{MPa}, 360{ }^{\circ} \mathrm{C}, 1 \mathrm{~h}$ and hydrogen/oil $600 \mathrm{~L} / \mathrm{L}$ as a function of data calculated by the three-lump model.

3) In the four-lump model for HDN, the shares of nitrogen in lumps 6,7 , 8 and 9 were $19.3,59.2,16.5$ and $5 \mathrm{wt} \%$, respectively. Their apparent activation energies were $82,123,150$ and $240 \mathrm{~kJ} / \mathrm{mol}$, respectively. Comparison of hydrogen pressure indexes showed that the HDN of feedstock was more affected by hydrogen pressure than HDS. Additionally, the HDN needed more severe operating conditions than the HDS because its apparent activation energies were higher than those of HDS. The predicted data showed that lump 9 was poorly converted in experimental conditions. The suitable operating conditions for $\mathrm{HDN}$ were $7 \mathrm{MPa}, 380^{\circ} \mathrm{C}$ and $1 \mathrm{~h}$, considering the influence of temperature, pressure and residence time predicted by the four-lump model.

4) The predicted reactive features and suitable operating conditions for HDS and HDN of Huadian shale oil MD agreed well with experimental results. The lumping kinetic model can be applied to simulating and optimizing the HDS and HDN reactions of shale oil MD hydrotreatment.

\section{Acknowledgements}

The authors are grateful for financial support from the Taishan Scholar Constructive Engineering Foundation of Shandong province, China (No. ts20120518), the Science Foundation of China University of Petroleum, Beijing (No. KYJJ2012-06-32), and the National Basic Research Program of China (No.2014CB744300). 


\section{REFERENCES}

1. Jialin Qian, Liang Yin. Oil Shale-Petroleum Alternative. China Petrochemical Press, Beijing, 2010.

2. Siirde, A., Roos, I., Martins, A. Estimation of carbon emission factors for the Estonian shale oil industry. Oil Shale, 2011, 28(1S), 127-139.

3. Weina Song, Yongli Dong, Limei Xue, Huixian Ding, Zhe Li, Guojiang Zhou. Hydrofluoric acid-based ultrasonic upgrading of oil shale and its structure characterization. Oil Shale, 2012, 29(4), 334-343.

4. Yue Ma, Shuyuan Li. The pyrolysis, extraction and kinetics of Buton oil sand bitumen. Fuel Process. Technol., 2012, 100, 11-15.

5. Cai Zeng, Sam Clayton, Hongwei Wu, Jun-ichiro Hayashi, and Chun-Zhu Li. Effects of dewatering on the pyrolysis and gasification reactivity of Victorian brown coal. Energ. Fuel., 2007, 21(2), 399-404.

6. Shuyuan Li. The developments of Chinese oil shale activities. Oil Shale, 2012, 29(2), 101-102.

7. Benyamna, A., Bennouna, C., Moreau, C., Geneste, P. Upgrading of distillate fractions of Timahdit Moroccan shale oil over a sulphided $\mathrm{NiO}-\mathrm{MoO}_{3} / \gamma-\mathrm{Al}_{2} \mathrm{O}_{3}$ catalyst. Fuel, 1991, 70(7), 845-848.

8. Hang Yu, Shuyuan Li, Guangzhou Jin. Hydrodesulfurization and hydrodenitrogenation of diesel distillate from Fushun shale oil. Oil Shale, 2010, 27(2), 126 134.

9. Holmes, S. A., Thompson, L. F. Nitrogen compound distributions in hydrotreated shale oil products from commercial-scale refining. Fuel, 1983, 62(6), 709-717.

10. Thompson, L. F., Holmes, S. A. Effect of multistage hydroprocessing on aromatic and nitrogen compositions of shale oil. Fuel, 1985, 64(1), 9-14.

11. Luik, H., Lindaru, E., Vink, N., Maripuu, L. Upgrading of Estonian shale oil distillation fractions. 1. Hydrogenation of the "diesel fraction". Oil Shale, 1999, 16(2), 141-148.

12. Luik, H., Vink, N., Lindaru, E., Maripuu, L. Upgrading of Estonian shale oil distillation fractions. 2. The effect of time and hydrogen pressure on the yield and composition of "diesel fraction" hydrogenation products. Oil Shale, 1999, 16(3), 249-256.

13. Luik, H., Maripuu, L., Vink, N., Lindaru, E. Upgrading of Estonian shale oil distillation fractions. 3. Hydrogenation of light mazute. Oil Shale, 1999, 16(4), 331-336.

14. Luik, H., Vink, N., Lindaru, E., Maripuu, L. Upgrading of Estonian shale oil distillation fractions. 4. The effect of time and hydrogen pressure on the yield and composition of light mazute hydrogenation products. Oil Shale, 1999, 16(4), 337-342.

15. Luik, H., Vink, N., Lindaru, E., Maripuu, L. Upgrading of Estonian shale oil distillation fractions. 5. Hydrogenation of heavy mazute. Oil Shale, 2000, 17(1), 25-30.

16. Luik, H., Luik, L., Krasulina, J., Riisalu, H. Upgrading Estonian shale oil bituminous fractions. In: 32nd Oil Shale Symposium, Colorado School of Mines, Golden, Colorado, October 15-19, 2012. 
17. Landau, M. V., Herskowitz, M., Givoni, D., Laichter, S., Yitzhaki, D. Mediumseverity hydrotreating and hydrocracking of Israeli shale oil. 1. Novel catalyst systems. Fuel, 1996, 75(7), 858-866.

18. Landau, M. V., Herskowitz, M., Givoni, D., Laichter, S., Yitzhaki, D. Medium severity hydrotreating and hydrocracking of Israeli shale oil - II. Testing of novel catalyst systems in a trickle bed reactor. Fuel, 1998, 77(1-2), 3-13.

19. Landau, M. V., Herskowitz, M., Givoni, D., Laichter, S., Yitzhaki, D. Medium severity hydrotreating and hydrocracking of Israeli shale oil: III. Hydrocracking of hydrotreated shale oil and its atmospheric residue for full conversion to motor fuels. Fuel, 1998, 77(14), 1589-1597.

20. Goelzer, A., Aarna, I. Progress towards installation of the Narva shale oil upgrader plant in Estonia. In: 30th Oil Shale Symposium, Colorado School of Mines, Golden, Colorado, October 18-22, 2010.

21. Williams, P. T., Chishti, H. M. Reaction of nitrogen and sulphur compounds during catalytic hydrotreatment of shale oil. Fuel, 2001, 80(7), 957-963.

22. Landau, M. V. Deep hydrotreating of middle distillates from crude and shale oils. Catal. Today, 1997, 36(4), 393-429.

23. Hang Yu, Shuyuan Li and Guangzhou Jin. Catalytic hydrotreating of the diesel distillate from Fushun shale oil for the production of clean fuel. Energ. Fuel., 2010, 24(8), 4419-4424.

24. Mederos, F. S., Elizalde, I., Ancheyta, J. Steady-state and dynamic reactor models for hydrotreatment of oil fractions: A review. Catal. Rev.-Sci. Eng., 2009, 51(4), 485-607.

25. Sertić-Bionda, K., Gomzi, Z., Šarić, T. Testing of hydrodesulfurization process in small trickle-bed reactor. Chem. Eng. J., 2005, 106(2), 105-110.

26. Harvey, T. G., Matheson, T. W., Pratt, K. C., Stanborough, M., S. Studies of the batch hydrotreatment of Rundle shale oil. Fuel, 1985, 64(7), 925-930.

27. Ho, T. C. Hydrodenitrogenation Catalysis. Catal. Rev.-Sci. Eng., 1988, 30(1), $117-160$

28. Weixiang Zhao, Dezhao Chen, Shangxu Hu. Differential fraction-based kinetic model for simulating hydrodesulfurization process of petroleum fraction. Comput. Chem., 2002, 26(2), 141-148.

29. Rodriguez, M. A., Elizalde, I., Ancheyta, J. Comparison of kinetic and reactor models to simulate a trickle-bed bench-scale reactor for hydrodesulfurization of VGO. Fuel, 2012, 100, 91-99.

30. Farag, H., Mochida, I. A comparative kinetic study on ultra-deep hydrodesulfurization of pre-treated gas oil over nanosized $\mathrm{MoS}_{2}$, CoMo-sulfide, and commercial CoMo/ $\mathrm{Al}_{2} \mathrm{O}_{3}$ catalysts. J. Colloid Interf. Sci., 2012, 372(1), 121129.

31. Te, M., Fairbridge, C., Ring, Z. Various approaches in kinetics modeling of real feedstock hydrodesulfurization. Petrol. Sci. Technol., 2003, 21(1-2), 157-181.

32. Fei Dai, Mingjie Gao, Chunshan Li, Shuguang Xiang, Suojiang Zhang. Detailed description of coal tar hydrogenation process using the kinetic lumping approach. Energ. Fuel., 2011, 25(11), 4878-4885.

33. Holmes, S. A., Thompson, L. F. Nitrogen compound distributions in hydrotreated shale oil products from commercial-scale refining. Fuel, 1983, 62(6), 709-717.

34. Bett, G., Harvey, T. G., Matheson, T. W., Pratt, K. C. Determination of polar compounds in Rundle shale oil. Fuel, 1983, 62(12), 1445-1454. 
35. Regtop, R. A., Crisp, P. T., Ellis, J. Chemical characterization of shale oil from Rundle, Queensland. Fuel, 1982, 61(2), 185-192.

36. Hongjun You, Chunming Xu, Jinsen Gao, Zhichang Liu, Pinxiang Yan. Nine lumped kinetic models of FCC gasoline under the aromatization reaction conditions. Catal. Commun., 2006, 7(8), 554-558.

37. Hang Yu, Shuyuan Li, Guangzhou Jin, Xun Tang. An analysis of the compositions of nitrogen and oxygen compounds in diesel distillate from Huandian shale oil. Petroleum Processing and Petrochemical, 2011, 42(3), 88-92 (in Chinese).

Presented by $V$. Oja

Received March 17, 2013 